\title{
Konsep Diri Anggota Komunitas Suporter PSS Sleman Berbasis Kampus
}

\author{
Ahmad Jihad Akbar Rewo (Correspondence Author) \\ UPN "Veteran" Yogyakarta, Indonesia \\ ahmadrewo.tugas@gmail.com \\ Haris Nur Wijayanto Aji \\ UPN "Veteran” Yogyakarta, Indonesia \\ Submitted: 18 December 2019; Revised: 2 March 2020; Accepted: 2 March 2020
}

\begin{abstract}
Brigata Curva Sud is a supporter group that influenced by "ultra" culture. This group doesn't have any structural leader such as other groups. The decision making process is done by a forum of communities and independent individuals inside the group. Campus Boys is one of such communities. While many communities are based on geographic proximity, Campus Boys is based on campuses. Members of this community are students of campuses all around Special Region of Yogyakarta. Researchers use George Herbert Mead's symbolic interactionism theory with descriptive qualitative method on member of PSS Sleman college based supporter group. Data is collected by interview and observation on interviewee and his environment. The results show that self-concept formed on member of PSS Sleman college based supporter group are showing-off their identity as a group, routinely attend the group's forum, organizing intellectual acts to show support for their club, supporting PSS Sleman on the stadium, and prioritizing their studies.

Keywords: Campus, PSS Sleman, Self-Concept Supporter.
\end{abstract}

\begin{abstract}
Abstrak
Brigata Curva Sud adalah suporter yang terpengaruh kultur "ultra" dari Eropa. Kelompok suporter ini tidak memiliki pemimpin struktural seperti suporter pada umumnya, tetapi melakukan forum dengan komunitas dan anggota independen yang tergabung di dalamnya. Salah satu komunitas yang ada di dalamnya adalah komunitas Campus Boys yang berbasis pada kampus-kampus. Berbeda dengan komunitas pada umumnya yang berbasis geografis, Campus Boys adalah komunitas berisikan kaum intelektual muda. Teori interaksi simbolis yang dikembangkan oleh George Herbert Mead digunakan sebagai pijakan penulis dalam mengembangkan ide dan paparan pembahasan. Metode penelitian yang digunakan adalah deskriptif kualitatif yang dilakukan pada anggota komunitas suporter PSS Sleman berbasis kampus. Pengumpulan data dilakukan melalui wawancara dan observasi terhadap lingkungan narasumber. Hasil penelitian menunjukkan konsep diri yang terbentuk pada anggota komunitas suporter PSS Sleman berbasis kampus yakni menunjukkan identitas komunitas dan tim kebanggan, rutin mengikuti forum komunitas, mengadakan kegiatan intelektual dengan tujuan mendukung PSS Sleman, mendukung PSS Sleman di stadion, dan tetap mengutamakan pendidikan.

Kata kunci: Kampus, Konsep Diri, PSS Sleman, Suporter.
\end{abstract}

\section{PENDAHULUAN}

Dengan adanya globalisasi dan perkembangan teknologi informasi dan komunikasi semakin memudahkan paparan budaya internasional terhadap budaya lokal. Hal ini tidak hanya terbatas pada budaya populer ( рор culture) tetapi juga subkultur yang ada pada masyarakat. Contoh kasus adalah budaya suporter di Indonesia. Budaya suporter Indonesia pada era sebelum 2010 lebih dikenal dengan budaya suporter "mania". Seiring dengan berjalannya teknologi informasi suporter Indonesia mulai terpapar budaya suporter Eropa yang terkenal dengan budaya "ultra" dan budaya "casual".

Ada dua pendekatan untuk mengidentifikasi munculnya kelompok suporter, terutama di Indonesia. Pertama yang berkembang melalui kultur atau budaya. Kelompok ini terbentuk secara organik lantaran disatukan oleh interaksi simbolik, seperti klub, logo, dan ragam nyanyian (chants) dukungan. Contoh paling bagus dari kelompok ini adalah kehadiran Bondho nekat alias Bonek (kelompok suporter Persebaya) dan Aremania (sebutan untuk pendukung tim Arema FC di Malang). Pendekatan kedua 
yang berkembang melalui struktural fungsional layaknya organisasi masyarakat (ormas). Contohnya Pasoepati di Solo, Brajamusti di Yogyakarta, atau Slemania di Sleman.

Ultras yang berkembang pesat di Italia mendatangi stadion untuk menunjukkan kegairahan berlebih saat mendukung tim andalannya bertanding. Menempati sudut tertentu di dalam stadion, biasanya di belakang gawang (alias curva), Ultras akan memberikan dukungan secara konsisten selama pertandingan berlangsung dipimpin oleh capo alias dirigen yang memegang megafon. Kelompok Ultras mewarnai stadion dengan gaya dukung teatrikal dengan beragam koreografi, kibaran panji-panji berukuran besar, chants, bila perlu menggunakan suar dan bom asap warna-warni karena stadion juga diibaratkan spektakel. Hal ini terkadang membuat mereka juga dapat menggunakan kekerasan.

Kelompok ultras memperlihatkan persamaan dan perbedaan di seluruh kebudayaan. Kepentingan dan praktik ultras di kota-kota di Indonesia sangat berkaitan dengan kepentingan politik lokal. Ultras memainkan peran penting dalam kehidupan sepakbola di Indonesia. Ultras di Indonesia berisikan anak-anak muda perkotaan yang mendedikasikan waktu luangya untuk mendukung klub kebanggannya (Fuller \& Junaedi, 2017).

Pionir suporter dengan gaya "ultra" adalah suporter PSS Sleman yang menempati Tribun Selatan Stadion Maguwharjo, atau yang dikenal sebagai Brigata Curva Sud atau BCS. Secara struktural BCS tidak memiliki pemimpin. Dalam mengambil keputusan dan sikap BCS mengadakan forum yang beranggotakan seluruh komunitas yang bergabung di dalamnya juga individu-individu yang tidak mengikuti komunitas (independen). Hasil forum ini kemudian dijadikan patokan kegiatan dan sikap BCS dalam mendukung PSS Sleman.

Komunitas-komunitas yang ada di dalam BCS ada bermacam-macam. Kebanyakan komunitas BCS biasanya berdasar pada geografis komunitas tersebut. Namun, ada juga yang berdasar pada pekerjaan atau komunitas intelektual. Contoh dari komunitas BCS berdasarkan komunitas intelektual adalah Campus Boys. Komunitas ini berbasis pada kampus-kampus di Daerah Istimewa Yogyakarta. Selain mendukung PSS Sleman di stadion, Campus Boys juga mengadakan aktivitas-aktivitas yang menggambarkan identitas mereka sebagai kaum intelektual muda.

\section{KERANGKA TEORI}

Konsep diri (self-concept) dibahas di dalam Interaction Symbolic Theory yang awalnya dimunculkan oleh John Dewey dan William James kemudian dikembangkan oleh George Herbert Mead (Chicago University) dan Manford Kuhn (Iowa University). Penelitian ini mengacu pada Interaction Symbolic Theory yang dikembangkan oleh Mead (West \& Turner, 2010).

Teori ini memiliki tiga asumsi: pertama, pentingnya makna bagi perilaku manusia; kedua, pentingnya self-concept; dan ketiga, hubungan antara individu dan masyarakat. Asumsi pertama mengatakan bahwa setiap individu membangun makna melalui proses komunikasi. Proses ini melibatkan partisipasi individu-individu untuk melakukan interpretive construction. Ada proses interaksi sosial dalam pemaknaan, sehingga bisa disimpulkan pemaknaan merupakan hasil dari berbagi ide, sekaligus makna yang dihasilkan disebarkan di antara individu-individu. Kata lain, makna terhadap sesuatu merupakan hasil kesepakatan bersama dan digunakan bersama.

Asumsi kedua tentang pentingnya self-concept menyatakan bahwa setiap individu memiliki persepsi yang relatif stabil tentang diri mereka. Penyebabnya adalah self-concept tidak terjadi secara tiba-tiba, namun hasil proses interaksi individu yang bersangkutan dengan individu-individu lainnya, misalnya dengan keluarga, teman dan guru. Jadi, individu mengembangkan self-concept melalui interaksi orang lain. Konsekuensinya, individu belajar memahami dirinya, tentang siapa dirinya dari interaksi dengan individu lain. 
Asumsi ketiga menyatakan bahwa budaya dan proses sosial mempengaruhi individu yang ada di dalamnya. Artinya, individu tidak sepenuhnya bebas dari nilai dan norma yang hidup di masyarakatnya. Pengaruh budaya dan proses sosial terjaga melalui pergaulan di masyarakat (atau social interaction). Persoalan gender muncul sebagai hasil budaya yang melingkupi hidup seseorang, di mana ia berinteraksi dan tumbuh sebagai individu. Tidak mengherankan jika kemudian lahirlah stereotipstereotip gender. Self-concept seseorang tidak terlepas dari stereotip yang dikenalnya. Self-concept yang terbentuk akan mempengaruhi segala motif dari tindakannya (Pincha, 2008).

Terdapat tiga komponen dalam konsep diri, yaitu: (a) attitude yakni sikap seseorang ketika menghadapi suatu kondisi tertentu; (b) beliefs yakni kepercayaan akan penerimaan yang dianggap benar dan (c) values yakni nilai yang menjadi pedoman bagi seseorang ketika melakukan sesuatu dan bertindak (Beebe, Beebe \& Ivy, 2010).

\section{METODE PENELITIAN}

Penelitian ini menggunakan metode studi kasus. Metode penelitian ini dilakukan diawali dengan pengumpulan data yang dilakukan dengan cara wawancara mendalam (in-depth interview), observasi dan studi pustaka. Wawancara mendalam dalam penelitian ini bersifat lentur dan terbuka, tidak memiliki struktur ketat, tidak dalam suasana formal dan bisa dilakukan berulang pada informan. Pertanyaan disusun dalam panduan wawancara, dimana yang paling signifikan dalam wawancara mendalam adalah mengajukan pertanyaan yang ada di panduan wawancara (interview guide) dan mengembangkannya ke dalam berbagai pertanyaan serta kemudian mencatat jawaban informan atas pertanyaan yang diajukan secara akurat (Neuman, 2000). Pemilihan informan menggunakan purposive sampling atau criterion-based selection. Sedangkan data observasi dicatat dalam catatan lapangan (fieldnote). Informan dalam penelitian ini adalah Kevin, observasi dilakukan dengan melakukan pengamatan mendalam tentang aktivitas dan lingkungan di sekitar informan. Setelah data terkumpul akan dilakukan reduksi, analisis dan sajian data.

Reduksi data dalam penelitian ini merupakan bagian proses seleksi, pemfokusan, penyederhanaan dan abstraksi data dari transkrip wawancara mendalam dan fieldnote. Analisis dilakukan dengan menggunakan teori-teori psikologi komunikasi yang relevan, dimana dalam penelitian ini teori yang digunakan adalah teori konsep diri. Sajian data merupakan suatu rakitan organisasi informasi, deskripsi dalam bentuk narasi yang memungkinkan simpulan penelitian dapat dilakukan. Sedangkan penarikan kesimpulan perlu diverifikasi agar cukup mantap dan bisa dipertanggungjawabkan. Oleh karena itu perlu dilakukan aktivitas pengulangan untuk tujuan pemantapan dan penelusuran data kembali dengan cepat. Verifikasi dapat juga dilakukan dengan usaha replikasi data yang lain dan mengembangkan ketelitian, sehingga simpulan penelitian menjadi lebih kokoh dan bisa dipercaya (Sutopo, 2000).

\section{HASIL DAN PEMBAHASAN}

Penelitian dilakukan pada lingkungan narasumber. Aktivitas narasumber berpusat pada Kampus II UPN "Veteran" Yogyakarta untuk berkuliah, warung kopi Secangkir Jawa pada forum komunitas Veteran Campus Boys, dan pertandingan PSS Sleman. Forum yang dilakukan oleh anggota Veteran Campus Boys biasanya dilaksanakan pada hari Senin malam. Dalam mendukung PSS Sleman, komunitas Campus Boys menempati bagian timur tribun selatan Maguwoharjo. Ditemukan beberapa penemuan mengenai kegiatan Veteran Campus Boys.

Dalam kegiatan sehari-hari anggota Veteran Campus Boys menggunakan pakaian yang menunjukkan identitas komunitas dan tim yang didukung. Atribut yang digunakan seperti jaket komunitas, baju komunitas, jersey PSS Sleman, dan kendaraan bersticker PSS Sleman. Pengenaan atribut bukan 
merupakan kesepakatan dari komunitas, tetapi kesadaran anggota komunitas atas identitas kelompok. Meskipun penggunaan atribut dapat menimbulkan insiden yang tidak diinginkan dengan kelompok suporter lain, Kevin tetap mengenakan atribut tersebut. Menurut Kevin, jika ada insiden yang tidak diinginkan dengan suporter lain adalah salah satu wadah menunjukkan keseriusan komunitas melindungi identitas dan kebanggaan.

Selain itu, diharapkan dengan menunjukkan identitas juga menjadi daya tarik bagi orang di luar komunitas. Dalam istilah yang digunakan anggota Veteran Campus Boys tujuan dari kegiatan tersebut adalah "PSS-kan Sekitarmu". Dalam menentukan kegiatan dan sikap, anggota Veteran Campus Boys mengadakan forum rutin setiap dua minggu sekali yang diadakan di warung kopi Secangkir Jawa. Forum ini wajib bagi anggota Veteran Campus Boys. Dalam forum ini dibahas langkah-langkah apa yang akan dilakukan oleh komunitas tersebut dalam mewujudkan hasil forum Brigata Curva Sud, juga melakukan evaluasi atas kegiatan yang telah mereka lakukan.

Forum yang diadakan bertujuan untuk menjalin solidaritas antar anggota komunitas, juga membentuk pemikiran yang sama akan pergerakan yang mereka lakukan. Anggota Veteran Campus Boys mengatakan bahwa forum adalah penjaga marwah pergerakan mereka, yaitu mendukung PSS dengan memberikan sumbangan baik secara konkrit maupun karya-karya intelektual. Veteran Campus Boys ingin menunjukkan perbedaan komunitas mereka dengan komunitas BCS lainnya. Apabila komunitas yang berbasis geografis cenderung mendukung dengan menonton PSS dan mengadakan acara musik bertemakan PSS, Veteran Campus Boys melakukan sesuatu yang berkaitan dengan kaum intelektual. Hal ini untuk menunjukkan identitas mereka sebagai intelektual muda.

Anggota Veteran Campus Boys melakukan kegiatan intelektual yang berkaitan dengan dukungan terhadap PSS Sleman yaitu dengan membuat artikel yang berkaitan dengan klub PSS Sleman. Selain itu, Veteran Campus Boys juga mengadakan pameran yang berkaitan dengan segala hal yang menyangkut klub PSS Sleman. Kegiatan tersebut dilatarbelakangi karena komunitas ini beranggotakan intelektualintelektual dari kampus, sehingga mereka menyalurkan rasa cinta mereka terhadap PSS Sleman dengan cara yang intelektual.

Selain berkegiatan dan mengenakan atribut, anggota Veteran Campus Boys juga selalu berusaha mengikuti pertandingan PSS Sleman secara langsung. Dengan datang secara langsung mereka memberikan pemasukan terhadap tim melalui tiket, dan juga memberikan dukungan moral dengan bernyanyi selama 90 menit. Dalam mendukung PSS Sleman mereka mengikuti aturan BCS sebagai induk komunitas. Sebelum masuk ke stadion anggota Campus Boys berkumpul terlebih dahulu di luar stadion Maguwoharjo untuk kemudian masuk secara bersamaan.

Lokasi Veteran Campus Boys di dalam stadion pun selalu mengikuti arahan dari struktural Campus Boys pusat, dimana mereka duduk di bagian timur tribun selatan Stadion Maguwoharjo. Selama 90 menit anggota Veteran Campus Boys tetap bernyanyi dan berdiri mendukung tim kebanggannya. Keberadaan komunitas menghadirkan suasana yang akrab di antara para anggota komunitas. Setelah selesai pertandingan anggota komunitas kemudian berkumpul kembali bercengkrama sebelum pulang. Khusus untuk Veteran Campus Boys mereka berkumpul terlebih dahulu di sebuah warung makan, untuk mengakrabkan sekaligus membahas kegiatan yang akan mereka lakukan secara kecil-kecilan.

Menurut Kevin, meskipun menjadi bagian suporter PSS Sleman, bukan berarti dia menomorduakan pendidikan. Baginya pendidikan tetap lah yang utama. Menjadi seorang yang berpendidikan akan membantu PSS dikemudian hari melalui bidang yang ia tekuni. Selain itu, menurutnya mendukung PSS tidak melulu mengenai menonton pertandingan secara langsung, tetapi juga melalui karya-karya intelektual yang dihadirkan. Melalui tulisan dan aksi peduli terhadap sekitar juga menunjukkan bukti dukungannya terhadap PSS Sleman. 
Anggota Veteran Campus Boys memiliki rasa gengsi dan superioritas terhadap rival. Kedua hal ini dapat dilihat pada pameran yang diadakan Campus Boys. Pada pameran itu ada foto bertuliskan "Beda Kasta. 4-0" yang merupakan skor akhir saat PSS Sleman bertemu rivalnya PSIM Jogja, 10 Oktober 2019, di Liga 2. Tulisan "beda kasta" diartikan PSS berhasil juara dan promosi ke Liga 1 pada musim yang sama, berbeda dengan rivalnya yang bertahan di Liga 2 .

Rivalitas seringkali berdasar pada perbedaan sosial yang kompleks dan mencolok atau perbedaan kebudayaan antara dua kelompok pendukung. Akan tetapi perlu dicatat, rivalitas tidak melulu mengenai perbedaan yang mencolok, sebuah rivalitas dapat muncul antar dua kelompok yang sangat serupa, disebut sebagai 'narcissism of minor differences' (Benkwitz \& Molnar, 2012).

Tiga komponen dalam konsep diri, yaitu: (a) attitude yakni sikap seseorang ketika menghadapi suatu kondisi tertentu; (b) beliefs yakni kepercayaan akan penerimaan yang dianggap benar dan (c) values yakni nilai yang menjadi pedoman bagi seseorang ketika melakukan sesuatu dan bertindak (Beebe, Beebe \& Ivy, 2010). Tiga komponen ini dapat dilihat dalam diri Sleman Fans berbasis kampus. Attitude yang berusaha ditunjukkan oleh Sleman Fans berbasis kampus adalah perilaku yang menggambarkan bagaimana seorang intelek menghadapi permasalahan dalam dunia sepakbola. Beliefs yang ditunjukkan oleh diri Sleman Fans berbasis kampus menunjukkan bahwa mereka percaya mereka merupakan representasi aktor intelektual dalam pergerakan suporter dan kedudukan mereka lebih tinggi dibandingkan rival timnya. Values yang dipegang oleh kelompok ini adalah turunan dari nilai-nilai yang juga dipegang oleh induk organisasi suporternya, yaitu Brigata Curva Sud, hal ini dapat dilihat dari cara pengambilan keputusan dan cara mendukung PSS Sleman secara langsung di stadion. Selain nilai-nilai yang diturunkan oleh induk organisasinya mereka memegang nilai-nilai kemahasiswaan karena ada kata “campus" yang tersemat pada nama organisasi mereka.

\section{KESIMPULAN}

Berdasarkan uraian hasil wawancara dan observasi pada temuan di lapangan maka dapat disimpulkan bahwa terdapat konsep diri yang terbentuk pada anggota komunitas suporter PSS Sleman berbasis kampus yakni menunjukkan identitas komunitas dan tim kebanggan, rutin mengikuti forum komunitas, mengadakan kegiatan intelektual dengan tujuan mendukung PSS Sleman, mendukung PSS Sleman di stadion, dan tetap mengutamakan pendidikan. Para anggota komunitas PSS Sleman berbasis kampus mengenakan atribut untuk menunjukkan identitas komunitas, menunjukkan kebanggaan akan identitas, dan berusaha mempengaruhi lingkungan sekitar untuk tertarik akan hal-hal berbau PSS Sleman. Untuk menjaga marwah komunitas dan pergerakan maka anggota komunitas menganggap perlu diadakannya forum untuk menentukan arah pergerakan dan menjaga solidaritas. Karena komunitas tersebut berisikan kaum intelektual muda maka hal-hal yang dilakukan untuk menunjukkan kecintaan mereka terhadap tim kebanggaannya juga dilakukan dengan hal-hal yang identik dengan kaum intelektual muda seperti penulisan artikel, dan pameran yang berkaitan dengan PSS Sleman. Selain mendukung melalui cara-cara yang intelek, anggota komunitas suporter PSS Sleman berbasis kampus juga mendukung tim kebanggaannya melalui hal-hal yang konkret seperti menonton langsung dan mendukung PSS Sleman di stadion. Dengan mendukung PSS Sleman secara langsung mereka memberikan dukungan secara finansial dan moral. Meskipun kehidupan sehari-hari anggota komunitas selalu berkaitan dengan PSS namun mereka tidak lupa akan kewajiban mereka sebagai intelektual muda, oleh karena itu mereka tetap mengutamakan studi, agar dapat membantu PSS dengan keahlian yang dimilikinya kelak. Anggota Veteran Campus Boys juga memiliki rasa gengsi dan superioritas terhadap rival. Konsep diri menjadi bagian penting dalam memahami pemikiran dan pergerakan suporter PSS Sleman yang berbasis kampus. Suporter bola yang selalu berasosiasi dengan kekerasan 
ternyata tidak selalu berbuntut pada hal-hal negatif. Komunitas suporter PSS Sleman yang berbasis di kampus adalah salah satu contoh bagaimana suporter bola mampu menjadi aktor intelektual pada saat yang bersamaan.

\section{REFERENSI}

Beebe, S. A., Beebe Susan J., \& Diana K Ivy. (2010). Communication Principles for A Lifetime. Boston: Pearson Education, Inc.

Benkwitz, Adam \& Molnar, Gyozo. (2012). Interpreting and exploring football fan rivalries: An overview. Soccer $\mathbb{E}$ Society. 13. 1-16. 10.1080/14660970.2012.677224.

Birowo, M.A., Widyastuti, D.A.R., \& Sidhi T.A.P. (2019). Konsep Diri Perempuan di Kawasan Rawan Bencana Gunung Merapi. Jurnal ASPIKOM, 4(1) 156-170.

Fuller, Andy \& Junaedi, Fajar. (2017). Ultras in Indonesia: conflict, diversification, activism. Sport in Society. 1-13. 10.1080/17430437.2017.1300392.

Neuman, Lawrence (2000). Social Research Methods : Qualitative and Quantitative Approaches, $4^{\text {th }}$ Edition. Boston, Allyn and Bacon

Pincha, C. (2008). Penanggulangan Bencana yang Peka Gender, Sebuah perangkat untuk Para Praktisi. Retrieved from http://gdnonline.org/resources/Pincha_GenderSensitiveDM_Bahasa Indonesia.pdf

Sutopo, HB (2000). Metode Penelitian Sosial Kualitatif. Solo, UNS Pers.

West, R. L., \& Turner, L. H. (2010). Introducing Communication Theory: Analysis and Application. Boston: McGraw-Hill. 